\title{
Prevention is better: the case of the underutilized failure mode effect analysis in patient safety
}

\author{
Lewis Goodrum ${ }^{1}$ and Prathibha Varkey ${ }^{2^{*}}$
}

\begin{abstract}
Prospective hazard analysis methodologies, like failure modes and effects analysis (FMEA), have been tried and tested in the engineering industry and are more recently gaining momentum in healthcare. Considering FMEA's evidence based successes, this commentary makes the case that healthcare is underutilizing the methodology by relying on retrospective hazard analysis. Healthcare leaders should determine where prospective hazard analysis principles could be better built into care delivery planning and processes that will enhance patient safety.
\end{abstract}

Keywords: Failure mode and effects analysis, Patient safety, Prospective hazard analysis, Healthcare management, Healthcare failure mode and effects analysis, Clinical quality, Patient safety tools

\section{Commentary}

The field of medicine has traditionally been built on a reactive approach of healing illness, rather than preventing it. Likewise, healthcare improvement has traditionally focused on improving existing processes and analyzing errors after they have occurred. In contrast, to arrive at the advanced safety levels, as seen in high reliability organizations, there is a need for commitment of top management commitment for the time and resources needed to advance the safety culture, and for trust in front-line employees to provide key input about the safety changes needed [1].

In a recent IJHPR article, Fanny Ofek et al. report on the use of prospective hazard analysis to implement policy change for intravenous potassium chloride (IV $\mathrm{KCl}$ ) administration. They review the impetus for change, criteria for selection of the failure mode and effect analysis (FMEA) methodology, and the patient safety enhancements that resulted from successful utilization of the methodology [2]. The authors discussed the motives for changing the policy and administration methods for IV $\mathrm{KCl}$, including to reduce the risk of accidental overdose of high-alert medications. The matter was urgent, impacted

\footnotetext{
* Correspondence: Prathibha.Varkey@ynhh.org

${ }^{2}$ Yale New Haven Health Northeast Medical Group, 99 Hawley lane, 3rd Flr,

Stratford, CT 06614, USA

Full list of author information is available at the end of the article
}

highly on patient safety, and was a notable change in treatment patterns. Utilization of the FMEA methodology was selected because Ofek et al. decided to prospectively intervene in harm reduction before the new policy was implemented.

Organizations always face competing priorities. Matrix and prioritization grids can provide assistance when trying to select patient safety projects in that context. They involve assessing criteria, such as urgency, level of impact, likeliness of occurrence, complexity, and anticipated value of the safety project [3-5]. FMEA methodology is similar to the matrix and prioritization grids in that it provides a systematic prioritization of factors. It differs uniquely, however, from other patient safety methodologies by being prospective, rather than retrospective.

A commonly used tool in the field of engineering, the FMEA has been used since the early 1990s to increase safety and consumer satisfaction, reduce cost, and reduce product time to market [6]. Several institutions, such as the Mayo Clinic, have adopted engineering principles more rapidly by including their engineering department as a part of the care team to bring process expertise to the table with clinicians. The engineers facilitate prospective hazard analysis when implanting new procedural techniques or adopting new technologies. In general, the healthcare industry has lagged behind other industries in 
adopting prospective hazard analysis by frequently relying on retrospective event analysis.

Since the early 2000s, the Veteran's Administration National Centre for Patient Safety has utilized a healthcare specific version of FMEA called healthcare failure mode and effect analysis (HFMEA) [7]. While FMEA and HFMEA work to accomplish the same goal of proactive hazard analysis, HFMEA modifies the FMEA hazard scoring processes and decision-making steps to bring more specificity to healthcare settings.

Retrospective event analysis, including root cause analysis, is similar to FMEA in that steps of process mapping, data analysis, and cause analysis must occur. One important distinction of root cause analysis from FMEA is that harm has already occurred and it is reactionary. In being reactive and retrospective, we continue to rely on analyses of errors after they have occurred, while not investing in building new safety processes and devices. In order to accelerate achievement of the patient safety ideal of zero preventable adverse events, prospective measures can and should be used with greater frequency.

Challenges involved in implementing FMEA and other prospective hazard analyses include investment in time and resources, training, and management commitment $[6,8]$. Considering the FMEA process step of assembling a multidisciplinary action team, including patient-facing caregivers, a modest time commitment as well is necessary to map the process and identify failure modes.

\section{Conclusions}

Ofek et al., through successful risk avoidance using the FMEA methodology, achieved much more than clinical quality and safety enhancements; they also increased the functional health and well-being of the population they served, reduced costs associated with complications, and achieved clinician and patient satisfaction with the process. Their outcomes demonstrate the value proposition behind preventing errors using prospective hazard analysis.

With recent publications suggesting that the epidemic of medical errors (now ranked third in leading causes of death in the US) persists, a re-look and overhaul of our current patient safety tools and processes seems imperative [9]. Future research should focus on determining the areas in healthcare where FMEA principles could be built into processes and devices prior to implementation, while continuing retrospective root cause analyses in situations where errors have occurred despite precautions.

\section{Acknowledgements}

None.

Funding

None.

Availability of data and materials

Data sharing not applicable to this article as no datasets were generated or analysed during the current study.

\section{Authors' contributions}

LG and Dr. PV co-authored the commentary. LG is lead author and Dr. PV is corresponding author. Both authors read and approved the final manuscript.

\section{Authors' information}

Lewis Goodrum is an administrative fellow with Yale New Haven Health System.

Dr. Prathibha Varkey is the President and Chief Executive Officer of Northeast Medical Group and Senior Vice President of Yale New Haven Health. She also serves as president of the American College of Medical Quality and she is an Adjunct Professor of Medicine and an Adjunct Professor of Preventive Medicine in the Mayo Clinic College of Medicine.

\section{Commentary on}

This is a commentary on DOI: 10.1186/s13584-016-0090-7

Competing interests

Both authors declare that they no competing interests.

Consent for publication

Not applicable.

Ethics approval and consent to participate

Not applicable.

\section{Author details}

${ }^{1}$ Yale New Haven Health, 2 Howe St., New Haven, CT 06511, USA. ${ }^{2}$ Yale New Haven Health Northeast Medical Group, 99 Hawley lane, 3rd Flr, Stratford, CT 06614, USA.

Received: 28 December 2016 Accepted: 30 December 2016 Published online: 20 February 2017

\section{References}

1. Hudson P. Implementing a safety culture in a major multi-national. Saf Sci. 2007;45(6):697-722.

2. Ofek F, Magnezi R, Kurzweil Y, Gazit I, Berkovitch S, Tal O. Introducing a change in hospital policy using FMEA methodology as a tool to reduce patient hazards. Isr J Health Policy Res. 2016;5(1):30.

3. Varkey, P. (Ed.). Medical quality management: theory and practice. Burlington: Jones \& Bartlett Publishers. 2010.

4. Dumbravă V, lacob VS. Using probability-impact matrix in analysis and risk assessment projects. Descrierea CIP/Description of CIP-Biblioteca Națională a României Conferința Internațională Educație și Creativitate pentru o Societate Bazată pe Cunoaștere-ŞTIINȚE ECONOMICE. 2013;42.

5. Hsieh YJ, Huang LY, Wang CT. A framework for the selection of six sigma projects in services: case studies of banking and health care services in Taiwan. Serv Bus. 2012;6(2):243-64.

6. Dale BG, Shaw P. Failure mode and effects analysis in the UK motor industry: a state-of-the-art study. Qual Reliab Eng Int. 1990;6(3):179-88.

7. DeRosier J, Stalhandske E, Bagian JP, Nudell T. Using health care failure mode and effect analysis ${ }^{\top \mathrm{M}}$ : the VA National Center for Patient Safety's prospective risk analysis system. Joint Comm J Qual Patient Saf. 2002;28(5):248-67.

8. Vincent CA. Analysis of clinical incidents: a window on the system not a search for root causes. Qual Saf Health Care. 2004;13(4):242-3.

9. Makary MA, Daniel M. Medical error - the third leading cause of death in the US. BMJ. 2016;353:12139. 